\title{
Delayed and time-cumulative toxicity of imidacloprid in bees, ants and termites
}

\author{
SUBJECT AREAS: \\ ENTOMOLOGY \\ ECOPHYSIOLOGY
}

\author{
Received \\ 11 February 2014 \\ Accepted \\ 5 June 2014 \\ Published \\ 4 July 2014
}

Correspondence and requests for materials should be addressed to N.D. (nicolas. desneux@sophia.inra.

\author{
Gary Rondeau', Francisco Sánchez-Bayo ${ }^{2}$, Henk A. Tennekes ${ }^{3}$, Axel Decourtye ${ }^{4}$, \\ Ricardo Ramírez-Romero 5 \& Nicolas Desneux ${ }^{6}$
}

\begin{abstract}
${ }^{1}$ Applied Scientific Instumentation, 1025 Elkay Drive, Eugene, Oregon 97405, USA, ${ }^{2}$ University of Sydney, Faculty of Agriculture \& Environment, 1 Central Avenue, Eveleigh, NSW 2015, Australia, ${ }^{3}$ Experimental Toxicology Services (ETS) Nederland BV, Frankensteeg 4, Zutphen, $7201 \mathrm{KN}$, The Netherlands, ${ }^{4}$ Association de Coordination Technique Agricole (ACTA), ITSAP-Institut de I'Abeille, UMT PrADE, Site Agroparc, 84914 Avignon, France, ${ }^{5}$ Departamento de Producción Agrícola, Universidad de Guadalajara, Zapopan, Jalisco, Mexico, ${ }^{6}$ French National Institute for Agricultural Research (INRA), Institut Sophia Agrobiotech, 400 route des chappes, 06903 Sophia-Antipolis, France.
\end{abstract}

Imidacloprid, one of the most commonly used insecticides, is highly toxic to bees and other beneficial insects. The regulatory challenge to determine safe levels of residual pesticides can benefit from information about the time-dependent toxicity of this chemical. Using published toxicity data for imidacloprid for several insect species, we construct time-to-lethal-effect toxicity plots and fit temporal power-law scaling curves to the data. The level of toxic exposure that results in $50 \%$ mortality after time $t$ is found to scale as $t^{1.7}$ for ants, from $\mathrm{t}^{1.6}$ to $\mathrm{t}^{5}$ for honeybees, and from $\mathrm{t}^{1.46}$ to $\mathrm{t}^{2.9}$ for termites. We present a simple toxicological model that can explain $\mathrm{t}^{2}$ scaling. Extrapolating the toxicity scaling for honeybees to the lifespan of winter bees suggests that imidacloprid in honey at $0.25 \mu \mathrm{g} / \mathrm{kg}$ would be lethal to a large proportion of bees nearing the end of their life.

T

he European Commission recently voted to place a moratorium on the use of three neonicotinoid insecticides (i.e. imidacloprid, thiamethoxam and clothianidin) after the European Food Safety Authority (EFSA) determined that there were "high acute risks" to bees from these products through several exposure routes ${ }^{1}$, e.g. by direct dust exposure during seed planting operations ${ }^{2}$, or by ingestion of residues in guttation droplets ${ }^{3}$, nectar and pollen from treated plants ${ }^{4}$. In their assessment of the risks from imidacloprid on bees, the EFSA considered toxic endpoints for acute (3.7 ng/bee) and chronic exposure $(20 \mu \mathrm{g} / \mathrm{kg}$ or L, henceforth $\mathrm{ppb})$ that represent a rough consensus of the toxicity studies reported in the literature (see review in ${ }^{5}$ ); however, they cautioned that there are no guidelines for chronic and sublethal exposure testing in bees, and expressed concern regarding the uncertainty about the biological significance of such exposures.

One way of resolving that uncertainty is to consider time as one of the exposure factors, such as concentration. Indeed, toxicity scaling with time can lend insight into the effects of residual pesticide contamination and can provide guidance to regulators for determining acceptable contamination levels.

Neonicotinoid insecticides are based on the natural toxin nicotine ${ }^{6}$, and are of particular concern because they bind virtually irreversibly to the nicotinic-acetylcholine receptors in the insect's nervous system ${ }^{7}$, so the damage can accumulate, and therefore the toxic effects can be reinforced with chronic exposure ${ }^{8}$. Time-to-effect studies lend themselves to a simple time-dependent power-law empirical model which can guide expectations for field toxicity effects ${ }^{9}$. Here we attempt to quantify risks to honeybees by considering the time-dependent toxicity of imidacloprid, the most ubiquitous of the neonicotinoid pesticides and the number one insecticide sales in the world ${ }^{10}$. The lethal time-to-effect relationship can be expressed as a power law

$$
L T 50 \propto D t^{p}
$$

where the toxic effect is the time when half of the insects succumb to the toxin (LT50), $D$ is the dose of toxin per unit time, and $\mathrm{P}$ is the power law exponent. A scaling relationship, such as Equation 1, is useful to extend predicted effects to low doses where experimental data do not exist.

There are only a few studies with honeybees that follow the insects beyond ten days, e.g. ${ }^{11}$, so we also looked at studies with ants and termites to corroborate the temporal toxicity dependence that we find in the honeybee studies. Finally, we consider a simple toxicological model to explain the experimental data. 


\section{Time-to-effect studies with terrestrial insects}

The studies analyzed here include cases where the exposure was by direct ingestion of the pesticidal toxin by adult honeybees and ants, a study where the toxin was fed to larvae of stingless bees, and finally a study of toxic exposure through treated soil for termites. Rust et al. ${ }^{12}$ reported time-dependent toxicity measurements for imidacloprid on Argentine ants, Linepithema humile (Mayr). Data for termites (Reticulitermes flavipes (Kollar)) were taken from Ramakrishnan et al. ${ }^{13}$, who reported mortality and feeding inhibition for termites observed up to 21 days in different soils treated with imidacloprid. The stingless bee Melipona quadrifasciata anthidioides Lepeletier, provides a good subject for studying the effect of the toxin on developing insects because the larva feeds only from food sealed inside the cell, so the total dose ingested can be accurately determined. The study by Tomé et al. ${ }^{14}$ followed these bees for 45 days from the egg until just after emerging as an adult over a wide range of toxic doses of imidacloprid.

For honeybees (Apis melifera L.), a paper by Suchail et al. ${ }^{15}$ and another by Dechaume-Moncharmont et al. ${ }^{16}$ report time-to-effect mortality data after chronic exposure to imidacloprid. However, there has been controversy about Suchail et al. results because two other studies did not show such a high sensitivity to the toxin ${ }^{17,18}$. Hence, we also include time-to-effect measurements from a study by the UK Department for Environment, Food and Rural Affairs $\left(\right.$ DEFRA $\left.^{19}\right)$, and a recent compilation of many researchers' acute median lethal doses (LD50) values for 24, 48, 72, and $96 \mathrm{~h}$ periods $\left(\right.$ FERA $\left.^{20}\right)$.

\section{Case studies}

Poisoning of adult insects by ingestion of imidacloprid. In order to plot the acute toxicity data along with chronic data on the same graph, average daily dose rates were calculated by dividing the acute LD50 values by the time intervals that were used for the measurement. For the chronic data, we use the reported concentration and consumption rates to obtain the daily dose rate. In both cases, the reported consumption of toxin (ng/day) is plotted versus the time of exposure until half the bees have died (LT50).

Most studies follow the insects for 10 days or less, so at low toxin concentrations the LT50 time cannot be reached. This is true for several of the data sets we analysed ${ }^{20}$, so whenever mortality is reached between $15 \%$ and $50 \%$ with respect to the control, we extrapolate from the last two time points to estimate the LT50. The paper by Dechaume-Moncharmont et al. ${ }^{16}$ contains a couple of data points with time-to-effect numbers for relatively low sublethal concentrations. Data from their paper (Figure 1) show that $4-8 \mu \mathrm{g} / \mathrm{L}$ (ppb) concentrations of imidacloprid in syrup eventually kill $50 \%$ of bees in about 30 days. Figure 1 also shows how we determine the LT50 point from the mortality time series using Abbott's formula ${ }^{21}$. LT50 times falling between reported sample points are linearly interpolated from neighboring points.

The data for poisoning of adult insects after ingesting imidacloprid are plotted in Figure 2. A power law best-fit line for each data set is also shown. The slope of the fitting line is $-1 / \mathrm{P}$, the exponent of power law Equation 1. For example, the LT50 times for the Argentine ants fit remarkably well a simple power law model with roughly $t^{1.7}$ dependence $\left(r^{2}=0.97, p=0.013\right)$. This adds confidence to the utility of the empirical power law model for imidacloprid with these social insects. Recall that simple accumulation to a toxic threshold (Haber's rule) would appear as directly proportional to time $\left(t^{1.0}\right)^{22}$. An exponent larger than one can be interpreted as coming from damaging secondary physiological effects that develop over time. We will come back to this interpretation later.

The DEFRA honeybee data stand out as not falling within the averages of many other researchers in the FERA report ${ }^{20}$; about a tenfold difference, despite a good fit to the power model $\left(r^{2}=0.99, \mathrm{p}\right.$ $<0.001)$. There appears to be a wide variation between experiments,
Imidacloprid

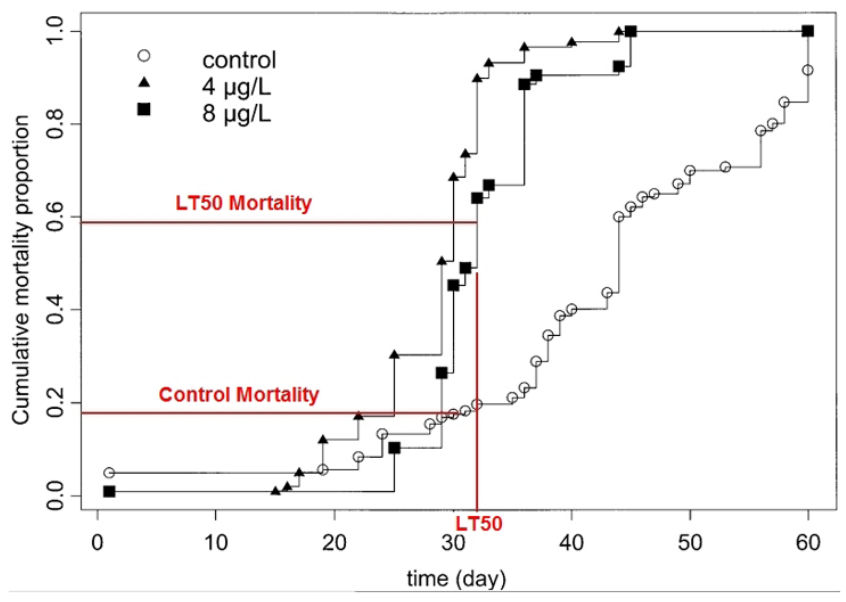

Figure 1 Time-to-effect curves for imidacloprid fed to honeybees at 4 and $8 \mu \mathrm{g} / \mathrm{L}$ in syrup (adapted from Dechaume-Moncharmont et al. ${ }^{16}$ ).

which could be due to the individual colony or strain of bees' sensitivity to this insecticide ${ }^{23}$,or by other factors not considered in the experimental design (temperature, season, condition of bees, nutritive status, etc.) The DEFRA study reports time-to-effect numbers and consumption data, so it provides a good data set for determining time scaling even if the DEFRA bees are not particularly representative of most other bees tested. The mortality for the DEFRA bees can be very well explained by the power law formulation with about $t^{1.6}$ dependence, very similar time exponent to the ants. Finally, the average LD50 values for 24, 48, 72, and 96 hours, compiled from many researchers, also fits the power law model $\left(\mathrm{r}^{2}=0.98, \mathrm{p}<\right.$ $0.001)$, here about $t^{2}$. The Dechaume-Moncharmont et al. ${ }^{16}$ data are included in this power fit line.

Dechaume-Moncharmont et al. ${ }^{16}$ results, using concentrations of 4 and $8 \mathrm{ppb},(0.08$ and $0.16 \mathrm{ng} /$ day, respectively) are relevant to field-realistic exposure levels. Residue concentrations of imidacloprid in pollen and nectar from treated agricultural crops are frequently reported in the 1 to $30 \mathrm{ppb}$ range in France ${ }^{24}$ and the US ${ }^{25}$. Bees foraging on those crops could be subject to the test levels used by Dechaume-Moncharmont et al. ${ }^{16}$, which caused $50 \%$ mortality in about 30 days.

The Suchail et al. ${ }^{15}$ results show a much higher sensitivity to imidacloprid than the trends we see with the other honeybee data sets in Figure 2. Rather than a $t^{2}$ dependence, lethal effects seem to scale as toxic concentration times $t^{5}\left(\mathrm{r}^{2}=0.87, \mathrm{p}=0.021\right)$. It is tempting to disregard the Suchail et al. ${ }^{15}$ results; however one test site in trials reported by Schmuck ${ }^{18}$ also showed very high sensitivity to a metabolite of imidacloprid (6-chloro-nicotinic acid) as well. That study reports 10 -day mortality at the Germany II location: control $10 \%$; $0.004 \mathrm{ng} /$ bee/d 67\%; $0.038 \mathrm{ng} /$ bee/day $77 \% ; 0.38 \mathrm{ng} /$ bee/day $97 \%$. Other locations did not show such high sensitivity to the insecticide. It is worth considering secondary stressors that could result in a higher sensitivity to the toxin. Suspects would be bacterial or viral pathogens or the Nosema microsporidian ${ }^{26}$, or even synergistic interaction with other insecticides ${ }^{27}$.

Compelling new research by Di Prisco, et al. found that very low doses of both the neonicotinoids clothianidin and imidacloprid caused immune suppression in honeybees as evidenced by replication of the deformed wing virus (DWV) ${ }^{28}$. They provided evidence that the neonicotinoids were downgrading the innate immunity pathway governed by NF- $\kappa \mathrm{B}$. Replication of the virus was found to increase with both dose and time.

Pathogen interactions with a host could lead to several timedependent processes. First, damage to the host immune system has 


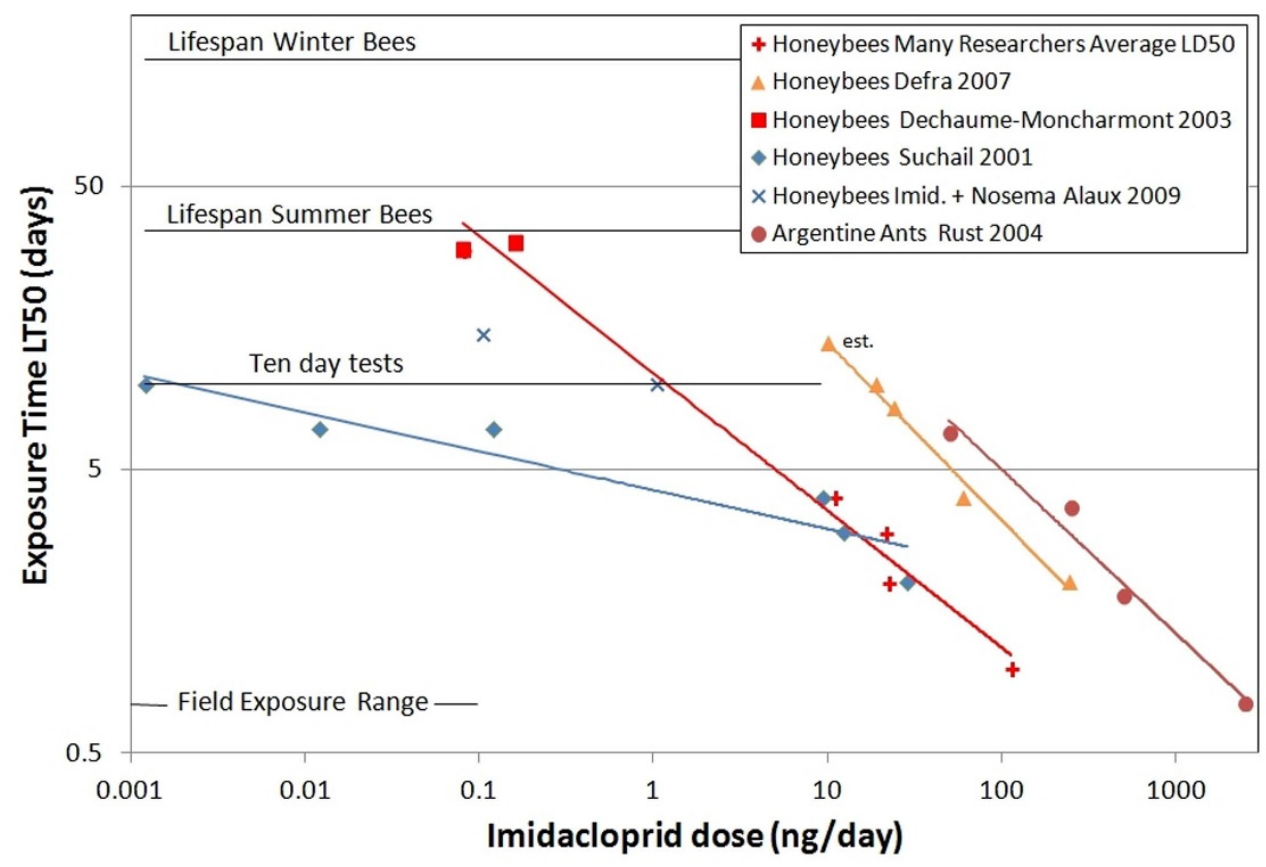

Figure $2 \mid$ Time-dependent toxicity from ingestion of imidacloprid for honeybees and Argentine ants. Published insect mortality results from several researchers plotted as time-to-effect versus daily dose per bee. Field exposure range assumes $<5 \mathrm{ppb}$ a.i. at $20 \mu \mathrm{l}$ consumption/day.

to occur for a pathogen to get a foothold. Then, before the host succumbs to the pathogen, the infectious organism must grow and multiply to lethal levels. Damage from the pathogen itself may take time to manifest in the host organism. Several of these timedependent processes, initiated by pesticide exposure, could produce a high order time dependency like that observed by Suchail et al ${ }^{15}$.

Addressing this question, the interaction between Nosema and imidacloprid was studied by Alaux et al. ${ }^{29}$. The study fed 200,000 Nosema spores to bees to initiate infection and then subjected the bees to various doses of imidacloprid. There was some interaction between the pesticide and the pathogen, but the study only followed the bees for ten days, so it is hard to draw conclusions at field-realistic imidacloprid doses, as the Nosema infection dominated the experiment at this short time scale. Nevertheless, two data points from that study are plotted in Figure 2 (crosses) where estimates could be made of the LT50 time with the addition of imidacloprid, using the Nosema infected bees as the control. However, imidacloprid-alone concentrations from 0.7 to $70 \mathrm{ppb}$ in that study resulted at day 10 in only about $7 \%$ to $12 \%$ mortality above the control, not sufficient to render an LT50 estimate.

Poisoning by ingestion of toxin in larvae. When imidacloprid is fed to developing larvae, the dose-time dependency is markedly different. Stingless Melipona bee workers will succumb to the toxin's effects between day 11 and day 19 of their development for a toxic dose range spanning more than two orders of magnitude: from 14 to $2800 \mathrm{ng} / \mathrm{bee}$, as shown in Figure $3^{14}$.

After the larval stage, the survival probability for the individuals making it to the pupae stage improves dramatically. At the lowest dose tested, $5.6 \mathrm{ng}$ imidacloprid a.i. in $130 \mu \mathrm{l}$ of larva food before sealing the cell, more than half of the bees survive well into adulthood, yet a third of that cohort died between day 11 and pupation at day 23. In this case the authors observed an almost dose-independent effect that caused mortality during a specific period of larval development. The time dependence for this section of the toxicity curve is $t^{13} !\left(\mathrm{r}^{2}=0.80, \mathrm{p}<0.001\right)$. This might also be (at least partially) due to the changing physiology of the developing insect, rather than to the cumulative effect. Moreover, the food uptake increases in the growing larva, thus increasing the exposure.
It is worth noting that had the authors followed the mortality of the larva for just ten days, as is common with adult honeybee toxicity studies, they would have missed the main feature of delayed toxicity which started at day 11. Similarly, mortality of honeybees in the Dechaume-Moncharmont et al. ${ }^{16}$ study started to occur about day 19 of exposure in the $4 \mathrm{ppb}$ concentration (Figure 1).

The greater survivability once the bees reach the pupae stage can be explained by two factors. First, the pupae are no longer consuming the toxin-laced larval food supply, so the internal concentration of toxicant would plateau or even decrease. More importantly, the insects continue to develop neurologically. A growth spurt of synaptic dendrites is known to occur at metamorphic transitions ${ }^{30}$ which would allow repair and recovery from previous damage in the surviving cohort. This mechanism may mean that larval sublethal exposure is only relevant for that stage of development, but largely irrelevant for insects that are further exposed as adults.

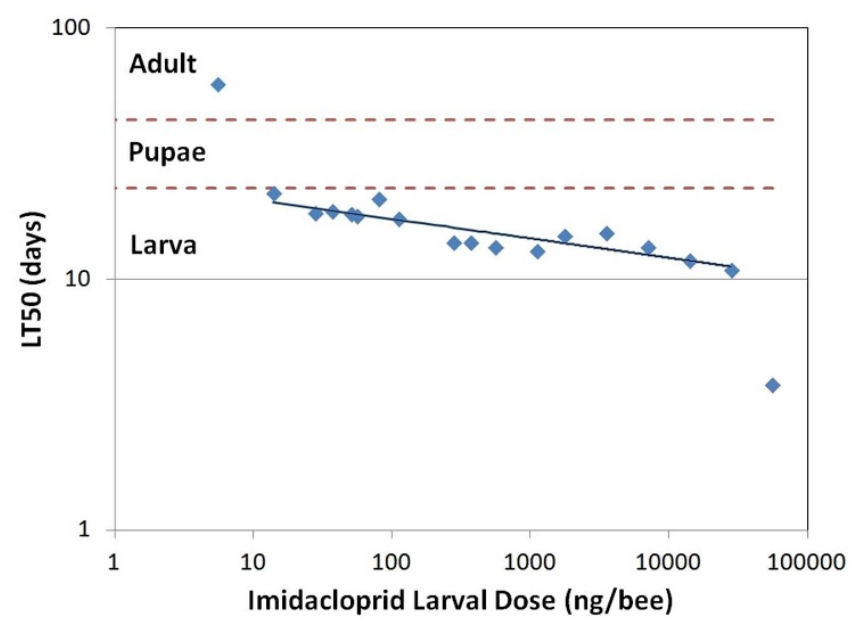

Figure 3 | Time-dependent toxicity for larval stingless bees fed imidacloprid (adapted from Tomé et al. ${ }^{14}$ ). 
Poisoning of termites in imidacloprid-treated soils. The previous studies refer to oral ingestion of imidacloprid. Moreover, time-todeath data for Reticulitermes termites exposed by contact to several imidacloprid-treated soils reveal a similar toxicity pattern (Figure 4). In this case, the power law model renders exponent values that range from 1.46 to 1.62 for loam and sandy-loam soils, respectively, to 2.6 in sand soil and 2.9 in clay-loam soils ( $\mathrm{r}^{2}$ range 0.73 to 0.94 , $\mathrm{p}$ range 0.005 to 0.045 ). The authors of that study ${ }^{13}$ explain that the different adsorption properties of each soil tested can account for the different exposure of the termites, hence the variable patterns of chronic toxicity. Besides the lethal endpoint, they also report significant feeding inhibition for termites in the imidacloprid-laced soils, possibly a contributor to the lethal effect, as observed also with bumble bees ${ }^{31}$. Although wide-ranging in absolute toxicity depending on the soil type, the time dependence of the toxic effects is similar to the other adult insects we have looked at above, with time exponents near two.

A Toxicity Model for neonicotinoids. Imidacloprid and all other neonicotinoids are designed to bind to the nicotinic acetylcholine receptors (nAChRs), which are located on the dendritic terminal membrane at the synapses of the insect nervous system ${ }^{6}$. When the neonicotinoid molecule binds to the $\mathrm{nAChR}$ the ion channel opens, as it would if it was stimulated normally by the acetylcholine (ACh) neurotransmitter; in other words, neonicotinoids are agonists that compete with the natural neurotransmitters. The neonicotinoid molecule remains bound to the $\mathrm{nAChR}$ in insects, holding the channel open, whereas normally ACh remains bound for only about a millisecond ${ }^{32}$ before dissociating from the receptor and being removed from the synaptic junction by the enzyme acetylcholinesterase (AChE). In mammals and other vertebrates, the lesser affinity of neonicotinoids for their nAChRs appears to be related to the different configuration of the subunits that make up this receptor, so the toxin binding is weak and/or does not last as long as in insects ${ }^{6}$.

A toxicokinetic-toxicodynamic model (TKTD) to explain the time-cumulative toxicity of imidacloprid shown above is proposed here. The model is also applicable for all neonicotinoids. The toxicokinetic portion of our model consists of a rate equation that describes accumulation of bound toxin on the synapses. We take the toxic exposure dose, $D(t)$, to be either a single initial dose or a continuous, much lower, chronic dose. The change in total-body toxic load, $C$, can be written

$$
\frac{d C}{d t}=D(t)-C / \tau_{M}+C_{B} / \tau_{D}
$$

where $\tau_{M}$ is the metabolic decay time. Neurotoxins produce an effect only when bound to specific receptors, so the toxicodynamic part of the model relies on the relative velocities of binding and dissociation to and from the receptor. Therefore, the amount of bound toxin, $C_{B}$, will depend upon the total toxic load and the time constants for receptor binding, $\tau_{A}$, and dissociation, $\tau_{D}$.

$$
\frac{d C_{B}}{d t}=C / \tau_{A}-C_{B} / \tau_{D}
$$

We assume here that there are plenty of binding sites and that the binding rate does not decrease because a large fraction of the sites become filled. However, one would expect that a very small percentage of the ion channels bound with toxin and held open continuously would be damaging to the organism; by way of analogy, it is like having a power switch turned on for a long time, squandering energy unnecessarily. Desensitisation, endocytosis or neuronal adaptation to the bound neonicotinoid could also occur, which we do not account for explicitly in our model other than through the empirically determined time constants.

It is less clear how the amount of bound neurotoxin produces toxic effect over time, even if there is ample evidence of it occurring $^{33}$. An explanation of the mechanisms leading from sublethal effects to delayed lethal effects over time needs to consider the specific mode of action of the toxin ${ }^{22}$. A likely candidate is the phenomenon of excitotoxicity, where prolonged and excessive stimulation of nerve cells leads to cell death from a variety of mechanisms $\mathrm{s}^{34}$. For example, continuous muscle stimulation by the affected nerve can lead to death of the muscle cell. Excessive stimulation of the synapse can lead to $\mathrm{Ca}^{++}$imbalance and demise of the nerve cell itself. Both of these mechanisms are the result of the accumulation of insults to the affected cells from synaptic stimulation over time. We can express the damaging biological effect, $\mathrm{E}(\mathrm{t})$, as

$$
\mathrm{E}(\mathrm{t}) \propto \int \mathrm{C}_{\mathrm{B}} \mathrm{dt}
$$

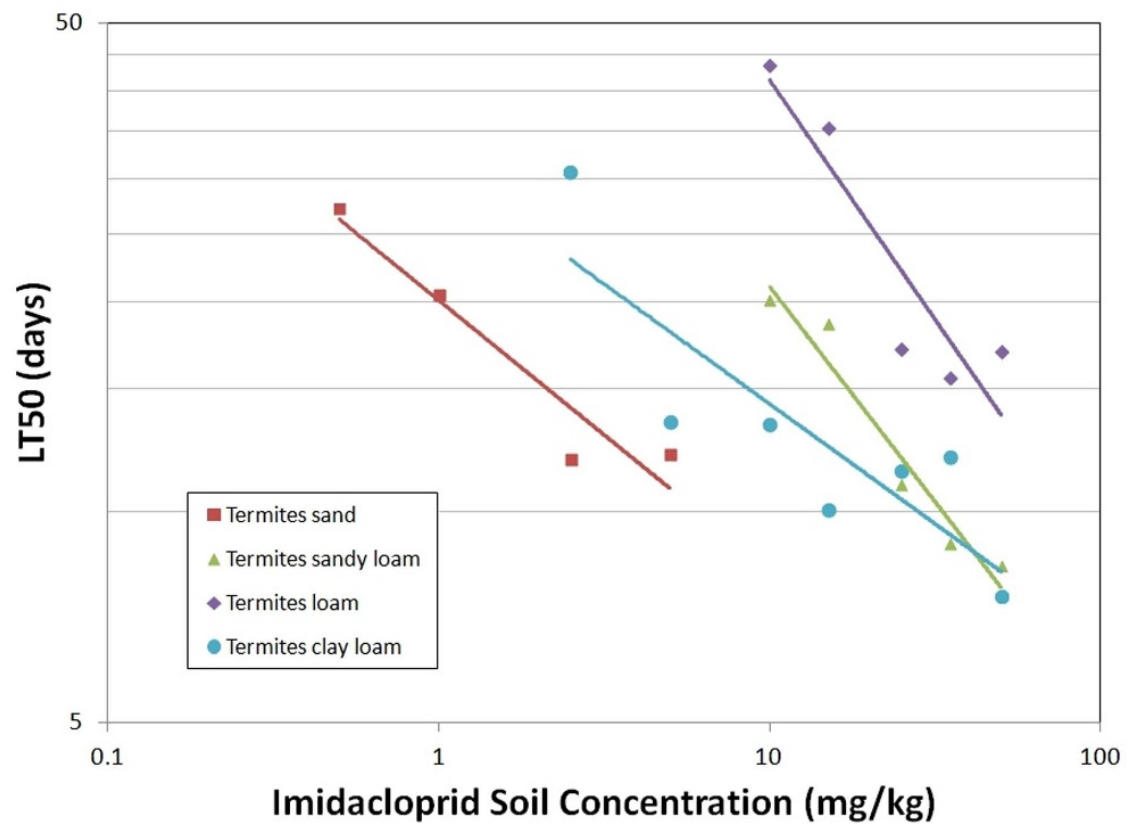

Figure 4 Toxicity of imidacloprid-treated soil to termites (data from Ramakrishnan et al. ${ }^{13}$ ). 


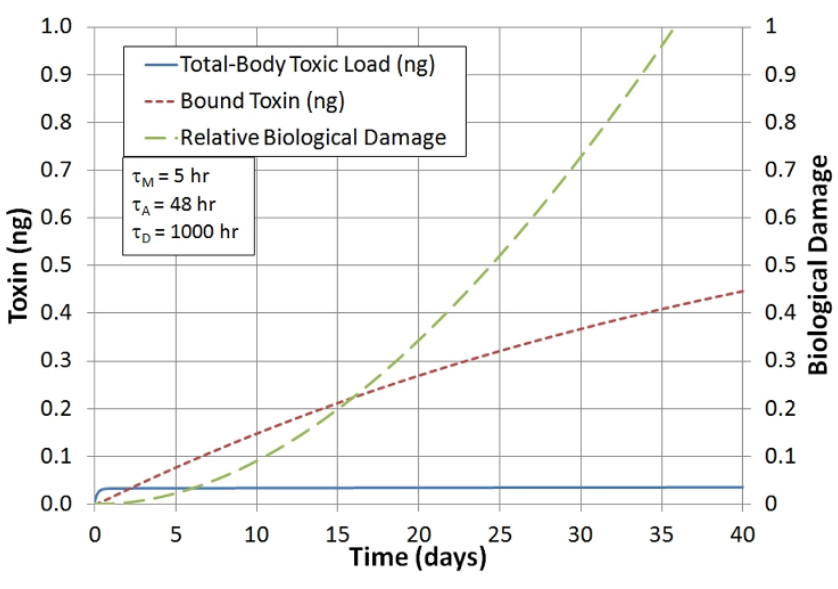

Figure $5 \mid$ Model results for chronic exposure of honeybees to imidacloprid at $0.16 \mathrm{ng} /$ day. Unbound total-body toxic load (solid line) is a small fraction of the daily intake because most of the toxin is metabolized while the amount of bound toxin (short dashes) grows linearly with time. Relative biological damage grows as $\mathbf{t}^{2}$. The model is scaled such that biological damage is unity at the point the LT50 is reached for honeybees.

We interpret a measured toxic endpoint to be where $E(t)$ reaches an arbitrary threshold, e.g. $E(t)=1.0$ corresponds to LT50.

To apply the model, we need estimates of kinetic time constants $\tau_{D}, \tau_{M}$ and $\tau_{A}$. Estimates for $\tau_{\mathrm{M}}$ and $\tau_{\mathrm{A}}$ are obtained from the radiocarbon metabolic analysis done by Suchail et al. ${ }^{35}$. Although the parent compound is quickly metabolized and excreted with a lifetime of about 5 hours, several toxic metabolites remain with a much slower apparent decay time ${ }^{35}$. Approximately $10 \%$ of the initial dose is still found in the insects after 72 hours as metabolites. This implies that the ratio $\tau_{\mathrm{M}} / \tau_{\mathrm{A}} \approx 0.1$. An accurate estimate of $\tau_{\mathrm{D}}$ was not possible, because the bees were only followed for 72 hours in Suchail et al. ${ }^{33}$ experiments, not long enough to establish the decay rate of the bound component. For irreversible binding, $\tau_{\mathrm{D}}$ would approach infinity.

An example of this simple model is shown in Figure 5 for chronic exposure of honeybees to imidacloprid at environmentally relevant oral doses of $0.16 \mathrm{ng} /$ day. The model is scaled so that at the observed LT50 of honeybees, the model's biological damaging effect, $\mathrm{E}(\mathrm{t})$, is approximately equal to one. In the chronic case, the total body toxic load remains at about $20 \%$ of the daily dose because the toxin is being continuously ingested and rapidly metabolized. However, the bound toxin that is trapped on synapses grows linearly, while the biological damage increases with $t^{2}$, and this outcome of the model matches very well the mortality observed in terrestrial insects (see Figures 2 and 4).

Further considerations of the model utility are discussed in the Supplementary Information (SI).

\section{Discussion}

At present, regulatory guidelines primarily assess the survival of adult honeybees after a short exposure to pesticides, acutely up to 4 days, and with chronic caged bee studies up to 10 days $^{36}$. However, some authors have stressed the importance of also testing for longer chronic toxicity, larval toxicity, and sublethal effects of pesticides ${ }^{37}$. Without explicit long term tests, we are left to estimate long term effects by extending the toxicity scaling that we find in shorter duration studies. We can extrapolate the curve in Figure 2, beyond the Dechaume-Moncharmont et al. ${ }^{16}$ data points with LT50 at about 30 days, to the lifespan of wintering bees at 150 days $^{38}$. The extrapolation suggests that daily ingestion of about $0.005 \mathrm{ng} /$ day of imidacloprid would produce LT50 in 150 days. For bees consuming $0.02 \mathrm{~g}$ honey per day ${ }^{4}$, this implies a concentration of $0.25 \mathrm{ppb}$ in honey as the lowest concentration capable of causing long-term mortality. Such a low concentration is about the detectable limit of this insecticide by LC/MS and below its limit of quantitation ${ }^{24}$. Hence, even with healthy bees, exposure to modest field-realistic residues of imidacloprid in pollen (range 0.5-30 ppb) and honey (range 0.7-13 ppb) could easily cause problems for summer bees and especially for longer-lived bees going through the winter. Certainly, not all pollen or honey are contaminated with imidacloprid, so the oral exposure of bees would be scaled down by a certain factor, since the average frequency of detection in pollen is between $9 \%$ and $40 \%$ for the US and France, respectively ${ }^{24,25,39}$.

Extrapolation of the toxicity curve should not be considered definitive, but rather cautionary. The toxicity scaling observed up to 30 days may not continue, as there is uncertainty in the actual decay rate of bound toxin molecules. Our model results suggest that decay times as short as 10 days are consistent with the observed data (See Figure S2). It is also likely that there are differences in the rate of food consumption and physiological differences between summer and winter bees that could affect the mortality rate $e^{40,41}$.

Colony health may not suffer significantly due to mortality of older bees as long as the colony remains otherwise healthy with a productive queen that is able to maintain the colony population. It is well known that colonies can compensate for the losses of worker bees. Indeed, full colony field studies on neonicotinoid treated crops show not much difference in performance between the insecticide treated and non-treated colonies ${ }^{41,42}$. Also, a field study investigating imidacloprid-treated maize found the level of contamination in stored honey was between $0.05 \mathrm{ppb}$ and $0.5 \mathrm{ppb}$, and yet mortality rates in apiaries were inversely correlated with the surface of maize fields treated but not with imidacloprid ${ }^{43}$. Additionally, risk analysis studies and reviews of neonicotinoid use have downplayed the importance of the neonicotinoids on honeybee losses, especially as the sole agent ${ }^{5,17,44}$. However, the explicit connection between innate immunity loss and the neonicotinoids ${ }^{28}$, was not known or considered in these studies. The potential for accumulation of neonicotinoids at receptor sites to the level where loss of innate immunity has been demonstrated may be much more likely for sublethal exposure to these chemicals than direct poisoning. Furthermore, it must be recognized that worker losses do occur, and declining homing rates can be accurately measured using radio frequency identification (RFID) $\operatorname{tags}^{45-47}$.

From the time-to-effect studies we have examined, in all cases it appears that imidacloprid lethal effects accumulate in the insects. Observations by many authors show that the longer the exposure time, the less amount of total chemical needed to kill the insects; in other words, the LD50s decrease with exposure time, as shown in Figures 2 to 4 . Whether it is enhanced, cumulative, or delayed toxicity, all these terms describe this situation when the power law scaling exponent is greater than one. One explanation is that the damage at cellular/tissue level might occur immediately after the first administration of the toxin, even if no permanent binding is observed. However, this damage might produce no immediate visible effect - mortality of the insect will occur later on. Thus there might be acute poisoning, with no mortality, during the initial phase of the experiment and its delayed lethal effect would increase the exponent value even if no toxin accumulation occurs.

Insecticides with delayed toxicity pose a particularly vexing problem when attempting to protect beneficial insects. Separation of residual toxin in time and space between target insect pests and pollinators becomes increasingly important as the order of time dependence increases. For example, consider a case where application of the pesticide is designed to kill target insects within 2 days. Assume that the pollinator lifespan is 50 days and we wish to not harm the pollinator. Further, assume that the 48 hour LD50 is the same for the target insect and pollinator (since they are both insects). The usual approach to protecting pollinators is to apply insecticide 
when bees are not present so the full force of the insecticide can act upon the target pest while only a residual amount will remain in the crop when bees encounter the pesticide. Table 1 shows the level of pesticide contamination compared to the application rate required to protect a long-lived pollinator, and the safety factors that need to be applied.

Compounds that exhibit enhanced toxicity require much more care for the toxin to be well-eliminated from the pollinator's environment. Systemic insecticides pose a particular risk in this regard, because once the toxin has been taken up in the plant, it can remain there for an extended period, including plant bloom, so their residues translocate to pollen and nectar ${ }^{48,49}$. Achieving the protection ratio required for pollinator safety may be impossible for long-lived compounds. Current regulatory standards emphasize a toxic threshold that does not include any time dependence. Utilizing a simple toxic threshold to define safe residual levels based on acute LD50s, which works for many pesticides, has led to complacency when faced with compounds that exhibit enhanced toxicity, such as imidacloprid and related chemicals. Compounds with a $t^{2}$ toxicity scaling require protection levels hundreds of time more stringent than those with merely a static lethal threshold (Table 1), because the ecotoxicological consequences of their delayed toxicity are potentially far-reaching. Many invertebrate species have long-lived stages of development in which delayed toxicity of residual pesticide could directly affect the organisms.

We examined studies that addressed bee mortality after exposure to imidacloprid. Bees thus affected may not immediately die, but they may be practically useless to the colony, as they may be unable to forage or navigate ${ }^{11,50-52}$, and hence become lost and perish outside the hive. Naturally, while some bees are lost, others are produced to replace them, so the population in the colony is compensated, making it difficult to estimate the actual mortality rates. Quantifying behavioral effects is more difficult than counting dead bees in a hive, and may require the use of sophisticated equipment to track down each individual bee ${ }^{53}$. We would expect that time-to-effect scaling for behavioral effects would be similar to the mortality data, but would merely show up sooner. Extrapolating from individual bee mortality or neurological damage to whole-colony health remains an important unresolved question. Neurological damage can effect foraging success and hence colony nutrition ${ }^{54}$, or grooming behavior, learning and olfactory sensory abilities ${ }^{50,55}$, which are important colony-wide responses to parasites and pathogens.

It is generally accepted that multiple pathogens ultimately bring down stressed colonies ${ }^{56,57}$. Cornman et al. ${ }^{57}$ found that Colony Collapse Disorder (CCD) colonies were more likely to have higher levels of a wide variety of pathogens than weak, but non-CCD, colonies. Not only were the levels of pathogens higher, but multiple agents were frequently found in combinations not typical of nonCCD colonies. It appears that the immune system in the CCD colonies has gone awry, and some authors hypothesize this is the case $\mathrm{e}^{58}$. Could it be a few parts per billion of insecticide that makes the difference? The Di Prisco study showed both imidacloprid and clothianidin adversely affect insect immunity and promote replication of a viral pathogen, DWV, in honey bees at exposure levels $1 \mathrm{ppb}$ or less with exposure of one to three days ${ }^{28}$. More research is still needed here, perhaps looking at pesticide interaction with KBV or AMPV virus, since these viruses show up in CCD colonies.

Aufauvre et al. ${ }^{59}$ looked at the interaction of the systemic insecticide fipronil and Nosema infection, and found a strong synergy between the pesticide and the pathogen, similar to what happened with imidacloprid ${ }^{29}$. Bees with either Nosema alone or fipronil alone suffered mortality similar to the control, since low doses of toxin and Nosema spores were used. However, given enough time, the combination was especially lethal. The study followed the bees for 22 days, the added time crucial for the delayed toxic and synergistic effects to show up.

The choice of Nosema as the pathogen for pesticide-pathogen interaction studies is convenient because the infection is easily accomplished with a spore solution, and the progress of the infection can be followed with microscopic examination of the bees ${ }^{26}$. Viruses are much more difficult to use as the infectious agent because of the difficulty of diagnosing their presence and quantifying the infectious dose and infection progress. However, viruses are more ubiquitous in honeybee colonies than Nosema, and could easily have a similar synergistic interaction with pesticides on the bee's health.

A final point to consider is the effect of imidacloprid on queen bees. Queen bees can live for several years. Queen bees also need to consume large amounts of food (e.g. honey and royal jelly) in order to churn out the quantity of eggs they lay every day. This makes queen bees especially susceptible to a cumulative toxin in the food supply. Queen failure was one of the precursors to colony mortality found by vanEngelsdorp et al. ${ }^{60}$. Equally, colonies of bumble bees (Bombus spp.) exposed to imidacloprid suffered an $85 \%$ reduction in production of new queens compared to control colonies ${ }^{61}$. The situation is aggravated when the bees are exposed to not just imidacloprid alone but two or more insecticides ${ }^{27}$, as it occurs in the real world. Queen failure, even if the bees succeed in raising a new one, will leave the colony without a fresh supply of young bees. A colony with pesticide stress may be relying on young bees to make up for those that disappear before their time.

\section{Conclusions}

Accurate time-to-effect scaling is an important tool for estimating the effect of chronic pesticide exposure to honeybees. In order to achieve this, chronic tests for pesticide toxicity to pollinators should be extended to 30 days or more and use time-to-effect measurements to clearly establish scaling. This is because in some experiments there were no deaths in either the control or exposed bees during the first 10 days $^{16}$, yet the toxic effect was clearly evident and different from the controls by day 30 . Similarly, with stingless bee larva, the growing larvae required at least 11 days before the toxic effects of imidacloprid became apparent. The model shown here reproduces well the observations made by many authors and explains the delayed and timecumulative toxicity of imidacloprid based on its mode of action. Toxins that have enhanced time-dependent chronic toxicity, such as imidacloprid and other neonicotinoids, need to be wellcharacterized to avoid accidental poisoning of beneficial organisms. It follows that compounds with delayed toxicity should be avoided as

Table 1 | Maximum residual insecticide contamination allowed to protect a long-lived pollinator (e.g. life-span 50 days) compared to the application rate when the insect pest is targeted in 2 days (Ratio pollinator/pest = 50/2). Assumes identical sensitivity to the toxin for both target and non-target insects. Relative safety factors $(x 3)$ required to protect the beneficial pollinator are indicated for each case

Pesticide toxicity time dependence

\section{$t^{0}$}

$t^{1}$

$t^{2}$
Residual Concentration compared to treatment level that kills non-target insects

$\begin{array}{ll}1 / 1 & 1 / 3 \\ 1 / 25 & 1 / 75 \\ 1 / 625 & 1 / 1875\end{array}$


pesticides because of the intrinsic difficulty they pose as environmental contaminants.

1. EFSA. Conclusion on the peer review of the pesticide risk assessment for bees for the active substance imidacloprid. EFSA J. 11, 3068, doi:10.2903/j.efsa.2013.3068 (2013).

2. Bortolotti, L. et al. Spring honey bee losses in Italy. Julius-Kuhn-Archiv 148-152 (2009).

3. Girolami, V. et al. Translocation of neonicotinoid insecticides from coated seeds to seedling guttation drops: A novel way of intoxication for bees. J. Econ. Entomol. 102, 1808-1815, doi:10.1603/029.102.0511 (2009).

4. Rortais, A., Arnold, G., Halm, M. P. \& Touffet-Briens, F. Modes of honeybees exposure to systemic insecticides: estimated amounts of contaminated pollen and nectar consumed by different categories of bees. Apidologie 36, 71-83, doi:10.1051/apido,2004071 (2005).

5. Blacquière, T., Smagghe, G., van Gestel, C. \& Mommaerts, V. Neonicotinoids in bees: a review on concentrations, side-effects and risk assessment. Ecotoxicology 21, 973-992, doi:10.1007/s10646-012-0863-x (2012).

6. Yamamoto, I. et al. Molecular mechanism for selective toxicity of nicotinoids and neonicotinoids. J. Pestic. Sci. 20, 33-40, doi:10.1584/jpestics.20.33 (1995).

7. Abbink, J. The biochemistry of imidacloprid. Pflanzen.-Nachr. Bayer 42, 183-195 (1991).

8. Tennekes, H. A. The significance of the Druckrey-Küpfmüller equation for risk assessment - The toxicity of neonicotinoid insecticides to arthropods is reinforced by exposure time. Toxicology 276, 1-4, doi:10.1016/j.tox.2010.07.005 (2010).

9. Sánchez-Bayo, F. From simple toxicological models to prediction of toxic effects in time. Ecotoxicology 18, 343-354, doi:10.1007/s10646-008-0290-1 (2009).

10. Jeschke, P., Nauen, R., Schindler, M. \& Elbert, A. Overview of the status and global strategy for neonicotinoids. J. Agric. Food Chem. 59, 2897-2908, doi:10.1021/ jf101303g (2011).

11. Ramírez-Romero, R., Chaufaux, J. \& Minh-Hà, P.-D. Effects of CrylAb protoxin, deltamethrin and imidacloprid on the foraging activity and the learning performances of the honeybee Apis mellifera, a comparative approach. Apidologie 36, 601-611, doi:10.1051/apido,2005039 (2005).

12. Rust, M. K., Reierson, D. A. \& Klotz, J. H. Delayed toxicity as a critical factor in the efficacy of aqueous baits for controlling Argentine ants (Hymenoptera: Formicidae). J. Econ. Entomol. 97, 1017-1024, doi:10.1603/00220493(2004)097[1017:dtaacf]2.0.co;2 (2004).

13. Ramakrishnan, R., Suiter, D. R., Nakatsu, C. H. \& Bennett, G. W. Feeding inhibition and mortality in Reticulitermes flavipes (Isoptera: Rhinotermitidae) after exposure to imidacloprid-treated soils. J. Econ. Entomol. 93, 422-428, doi:10.1603/0022-0493-93.2.422 (2000)

14. Tomé, H. V. V., Martins, G. F., Lima, M. A. P., Campos, L. A. O. \& Guedes, R. N. C. Imidacloprid-induced impairment of mushroom bodies and behavior of the native stingless bee Melipona quadrifasciata anthidioides. PLoS One 7, e38406, doi:10.1371/journal.pone.0038406 (2012).

15. Suchail, S., Guez, D. \& Belzunces, L. P. Discrepancy between acute and chronic toxicity induced by imidacloprid and its metabolites in Apis mellifera. Environ. Toxicol. Chem. 20, 2482-2486, doi:10.1002/etc.5620201113 (2001).

16. Dechaume-Moncharmont, F.-X., Decourtye, A., Hennequet-Hantier, C., Pons, O. \& Minh-Hà, P.-D. Statistical analysis of honeybee survival after chronic exposure to insecticides. Environ. Toxicol. Chem. 22, 3088-3094, doi:10.1897/02-578 (2003).

17. Cresswell, J. A meta-analysis of experiments testing the effects of a neonicotinoid insecticide (imidacloprid) on honey bees. Ecotoxicology 20, 149-157, doi:10.1007/ s10646-010-0566-0 (2011)

18. Schmuck, R. Effects of a chronic dietary exposure of the honeybee Apis mellifera (Hymenoptera: Apidae) to imidacloprid. Arch. Environ. Contam. Toxicol. 47, 471-478, doi:10.1007/s00244-004-3057-6 (2004).

19. DEFRA. Assessment of the risk posed to honeybees by systemic pesticides. (Department for Environment, Food and Rural Affairs, 2007).

20. FERA. Neonicotinoid Pesticides and Bees. Report to Syngenta Ltd., (Food and Environment Research Agency, 2013).

21. Abbott, W. S. A method of computing the effectiveness of an insecticide. J. Econ. Entomol. 18, 265-267 (1925)

22. Tennekes, H. A. \& Sánchez-Bayo, F. The molecular basis of simple relationships between exposure concentration and toxic effects with time. Toxicology 309, 39-51, doi:10.1016/j.tox.2013.04.007 (2013).

23. Laurino, D., Manino, A., Patetta, A. \& Porporato, M. Toxicity of neonicotinoid insecticides on different honey bee genotypes. Bull. Insectology 66, 119-126 (2013).

24. Chauzat, M.-P. et al. An assessment of honeybee colony matrices, Apis mellifera (Hymenoptera: Apidae) to monitor pesticide presence in continental France. Environ. Toxicol. Chem. 30, 103-111, doi:10.1002/etc.361 (2011).

25. Rennich, K. et al. 2011-2012 National Honey Bee Pests and Diseases Survey Report. 17 (USDA, 2012).

26. Pettis, J., vanEngelsdorp, D., Johnson, J. \& Dively, G. Pesticide exposure in honey bees results in increased levels of the gut pathogen Nosema. Naturwissenschaften 99, 153-158, doi:10.1007/s00114-011-0881-1 (2012).
27. Gill, R. J., Ramos-Rodriguez, O. \& Raine, N. E. Combined pesticide exposure severely affects individual- and colony-level traits in bees. Nature 491, 105-108, doi:10.1038/nature11585 (2012).

28. Di Prisco, G. et al. Neonicotinoid clothianidin adversely affects insect immunity and promotes replication of a viral pathogen in honey bees. PNAS 110, 18466-18471, doi:10.1073/pnas.1314923110 (2013).

29. Alaux, C. et al. Interactions between Nosema microspores and a neonicotinoid weaken honeybees (Apis mellifera). Environ. Microbiol. 12, 774-782, doi:10.1111/ j.1462-2920.2009.02123.x (2010).

30. Levine, R. B. \& Truman, J. W. Metamorphosis of the insect nervous system: changes in morphology and synaptic interactions of identified neurones. Nature 299, 250-252, doi:10.1038/299250a0 (1982).

31. Laycock, I., Lenthall, K., Barratt, A. \& Cresswell, J. Effects of imidacloprid, a neonicotinoid pesticide, on reproduction in worker bumble bees (Bombus terrestris). Ecotoxicology 21, 1937-1945, doi:10.1007/s10646-012-0927-y (2012).

32. Beadle, D. J., Horseman, G., Pichon, Y., Amar, M. \& Shimahara, T. Acetylcholineactivated ion channels in embryonic cockroach neurones growing in culture. J. Exp. Biol. 142, 337-355 (1989).

33. Desneux, N., Decourtye, A. \& Delpuech, J.-M. The sublethal effects of pesticides on beneficial arthropods. Annu. Rev. Entomol. 52, 81-106 (2007).

34. Milatovic, D., Gupta, R. C. \& Aschner, M. Anticholinesterase toxicity and oxidative stress. The Scientific World JOURNAL 6, 295-310, doi:10.1100/ tsw.2006.38 (2006)

35. Suchail, S., Debrauwer, L. \& Belzunces, L. P. Metabolism of imidacloprid in Apis mellifera. Pest Manage. Sci. 60, 291-296, doi:10.1002/ps.772 (2004).

36. EFSA. Towards an integrated environmental risk assessment of multiple stressors on bees: review of research projects in Europe, knowledge gaps and recommendations. EFSA J. 12, 3594, doi:10.2903/j.efsa.2014.3594 (2014).

37. Decourtye, A., Henry, M. \& Desneux, N. Overhaul pesticide testing on bees. Nature 497, 188, doi:10.1038/497188a (2013).

38. Free, J. B. \& Spencer-Booth, Y. The longevity of worker honey bees (Apis mellifera). Proc. R. Entomol. Soc. Lond. A 34, 141-150, doi:10.1111/j.13653032.1959.tb00230.x (1959).

39. Mullin, C. A. et al. High levels of miticides and agrochemicals in North American apiaries: implications for honey bee health. PLoS One 5, e9754, doi:10.1371/ journal.pone.0009754 (2010).

40. Schmuck, R., Schöning, R., Stork, A. \& Schramel, O. Risk posed to honeybees (Apis mellifera L, Hymenoptera) by an imidacloprid seed dressing of sunflowers. Pest Manage. Sci. 57, 225-238, doi:10.1002/ps.270 (2001).

41. Faucon, J.-P. et al. Experimental study on the toxicity of imidacloprid given in syrup to honey bee (Apis mellifera) colonies. Pest Manage. Sci. 61, 111-125, doi:10.1002/ps.957 (2005).

42. Stadler, T., Martinez Gines, D. \& Buteler, M. Long-term toxicity assessment of imidacloprid to evaluate side effects on honey bees exposed to treated sunflower in Argentina. Bull. Insectology 56, 77-81 (2003).

43. Nguyen, B. K. et al. Does imidacloprid seed-treated maize have an impact on honey bee mortality? J. Econ. Entomol. 102, 616-623 (2009).

44. Staveley, J. P., Law, S. A., Fairbrother, A. \& Menzie, C. A. A causal analysis of observed declines in managed honey bees (Apis mellifera). Hum. Ecol. Risk Assess. 20, 566-591, doi:10.1080/10807039.2013.831263 (2014).

45. Ohashi, K., D'Souza, D. \& Thomson, J. D. An automated system for tracking and identifying individual nectar foragers at multiple feeders. Behav. Ecol. Sociobiol. 64, 891-897 (2010)

46. Henry, M. l. et al. A common pesticide decreases foraging success and survival in honey bees. Science 336, 348-350, doi:10.1126/science.1215039 (2012).

47. Feltham, H., Park, K. \& Goulson, D. Field realistic doses of pesticide imidacloprid reduce bumblebee pollen foraging efficiency. Ecotoxicology 23, 317-323 (2014).

48. Stoner, K. A. \& Eitzer, B. D. Movement of soil-applied imidacloprid and thiamethoxam into nectar and pollen of squash (Cucurbita pepo). PLoS One 7 , e39114, doi:10.1371/journal.pone.0039114 (2012).

49. Sánchez-Bayo, F., Tennekes, H. A. \& Goka, K. in Insecticides - Development of Safer and More Effective Technologies (ed Trdan, S) Ch. 13, 365-414 (InTech, 2013).

50. Decourtye, A. et al. Imidacloprid impairs memory and brain metabolism in the honeybee (Apis mellifera L.). Pestic. Biochem. Physiol. 78, 83-92, doi:10.1016/ j.pestbp.2003.10.001 (2004).

51. Palmer, M. J. et al. Cholinergic pesticides cause mushroom body neuronal inactivation in honeybees. Nat. Commun. 4, 1634, doi:10.1038/ncomms 2648 (2013).

52. Han, P., Niu, C., Lei, C., Cui, J. \& Desneux, N. Use of an innovative T-tube maze assay and the proboscis extension response assay to assess sublethal effects of GM products and pesticides on learning capacity of the honey bee Apis mellifera L. Ecotoxicology 19, 1612-1619, doi:10.1007/s10646-010-0546-4 (2010).

53. Decourtye, A. et al. Honeybee tracking with microchips: a new methodology to measure the effects of pesticides. Ecotoxicology 20, 429-437, doi:10.1007/s10646 011-0594-4 (2011).

54. Schneider, C. W., Tautz, J., Grünewald, B. \& Fuchs, S. RFID tracking of sublethal effects of two neonicotinoid insecticides on the foraging behavior of Apis mellifera. PLoS One 7, e30023, doi:10.1371/journal.pone.0030023 (2012)

55. Ramirez-Romero, R., Desneux, N., Decourtye, A., Chaffiol, A. \& Minh-Hà, P.-D. Does Cry1Ab protein affect learning performances of the honey bee Apis mellifera 
L. (Hymenoptera, Apidae)? Ecotoxicol. Environ. Saf. 70, 327-333, doi:10.1016/ j.ecoenv.2007.12.002 (2008).

56. VanEngelsdorp, D. et al. Weighing risk factors associated with Bee Colony Collapse Disorder by classification and regression tree analysis. J. Econ. Entomol. 103, 1517-1523, doi:10.1603/ec09429 (2010).

57. Cornman, R. S. et al. Pathogen webs in collapsing honey bee colonies. PLoS One 7, e43562, doi:10.1371/journal.pone.0043562 (2012).

58. Mason, R., Tennekes, H., Sánchez-Bayo, F. \& Jepsen, P. U. Immune suppression by neonicotinoid insecticides at the root of global wildlife declines. J. Environ. Immunol. Toxicol. 1, 3-12, doi:10.7178/jeit.1 (2013).

59. Aufauvre, J. et al. Parasite-insecticide interactions: a case study of Nosema ceranae and fipronil synergy on honeybee. Sci. Rep. 2, 326, doi:10.1038/srep00326 (2012).

60. vanEngelsdorp, D., Tarpy, D. R., Lengerich, E. J. \& Pettis, J. S. Idiopathic brood disease syndrome and queen events as precursors of colony mortality in migratory beekeeping operations in the eastern United States. Preventive Veterinary Medicine 108, 225-233, doi:10.1016/j.prevetmed.2012.08.004 (2013).

61. Whitehorn, P. R., O'Connor, S., Wackers, F. L. \& Goulson, D. Neonicotinoid pesticide reduces bumble bee colony growth and queen production. Science 336, 351-352, doi:10.1126/science.1215025 (2012)

\section{Author contributions}

G.R. and F.S.B. analyzed the data, G.R., F.S.B. and H.A.T. worked out the toxicity model, G.R., F.S.B., H.A.T., A.D., R.R.R. and N.D. shared in the scoping and writing responsibilities.

\section{Additional information}

Supplementary information accompanies this paper at http://www.nature.com/ scientificreports

Competing financial interests: The authors declare no competing financial interests.

How to cite this article: Rondeau, G. et al. Delayed and time-cumulative toxicity of imidacloprid in bees, ants and termites. Sci. Rep. 4, 5566; DOI:10.1038/srep05566 (2014).

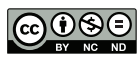

This work is licensed under a Creative Commons Attribution-NonCommercialNoDerivs 4.0 International License. The images or other third party material in this article are included in the article's Creative Commons license, unless indicated otherwise in the credit line; if the material is not included under the Creative Commons license, users will need to obtain permission from the license holder in order to reproduce the material. To view a copy of this license, visit http:// creativecommons.org/licenses/by-nc-nd/4.0/ 